\title{
CRISIS DE LA GLOBALIZACIÓN, EL REGIONALISMO Y EL ORDEN LIBERAL: EL ASCENSO MUNDIAL DEL NACIONALISMO Y LA EXTREMA DERECHA*
}

Crisis of globalization, regionalism and the liberal order: the world climb of nationalism and the extreme right

\author{
José Antonio Sanahuja \\ Instituto Complutense de Estudios Internacionales \\ Universidad Complutense de Madrid \\ sanahuja@cps.ucm.es \\ https://orcid.org/0000-0002-6806-5498
}

Recibido: $16 / 10 / 2018$

Aprobado: 21/2/2019

Resumen: Diez años después de iniciarse la crisis económica global, una nueva revolución tecnológica y productiva parece dejar atrás la globalización como etapa histórica, tal y como esta se definió a mediados de los años noventa. Pero el factor más importante que explica ese cambio es la tendencia global que, más allá de especificidades nacionales, comporta el ascenso del nacionalismo y de la ultraderecha en el sistema internacional. Ese ascenso es el resultado de un proceso de repolitización y contestación de las normas e instituciones del orden internacional liberal. En este trabajo se examinan los factores causales del ascenso de la extrema derecha y su proyección al escenario internacional a través de la nueva matriz de política exterior de corte nacionalista, impulsada por los nuevos patriotas en el poder en Estados Unidos, Rusia, China, Brasil y otros países.

Palabras clave: globalización; extrema derecha; nacionalismo; regionalismo; orden internacional.

\footnotetext{
* En este trabajo el autor actualiza y refina otros anteriores sobre la crisis de la globalización y el orden internacional liberal, como parte de una línea de trabajo iniciada en 2017. Una versión anterior se presentó en la conferencia ISA-FLACSO celebrada en Quito en julio de 2018.
} 


\begin{abstract}
Ten years after the start of the global economic crisis, revolutionary changes in technology and production seems to close globalization as an historical phase, as it was defined in the mid-nineties. But the most important factor that explains this change is the global trend that, beyond national specificities, is defined by the rise in the international system of nationalism and of the extreme right. This rise is the outcome of a process of re-politicization and contestation of the norms and institutions of the international liberal order. This paper examines the causal factors of the rise of the extreme right, and its projection to the international scene through the new matrix of nationalist-style foreign policy driven by the new patriots in power in the United States, Russia, China, Brazil and other countries.
\end{abstract}

Keywords: globalization; extreme right; nationalism; regionalism; world order. 


\section{Crisis de la globalización y fin de un ciclo histórico: estructura y agencia}

¿Qué significación tendrá la crisis económica de 2008 en los libros de historia del futuro? Siendo la más grave recesión de la historia contemporánea desde el crack de 1929 y la Gran Depresión, ya se encuentra entre los hitos que han marcado el inicio del siglo XXI. Pero la historiografía futura quizás otorgue a ese acontecimiento un significado mayor: el de hito o parteaguas que marca el fin de la etapa de la globalización, al menos tal y como se la definió con el cambio de milenio.

Es cierto que los límites temporales de la globalización son bastante imprecisos, pero en retrospectiva parece un ciclo claramente identificable: se iniciaría en los años ochenta del siglo pasado como etapa dominada por la expansión global del mercado de capitales, nuevos patrones de producción basados en cadenas de suministro transnacionales, y liberalización comercial y financiera, vía programas de ajuste estructural y acuerdos de libre comercio, en el caso de los países en desarrollo; vía apertura económica en Europa oriental, tras la caída del bloque del Este; mercado único en la UE, o capitalismo de Estado en el caso de China. Esa etapa, que se prolongó durante 35 años, ha sido más larga, y tal vez de efectos más profundos que el ciclo anterior de la Guerra Fría y expansión económica de posguerra hasta la ruptura del sistema de Bretton Woods y la crisis del petróleo, a inicios de los años setenta.

Dominada por un amplio consenso en torno al liberalismo económico, y no tan amplio en torno a la democracia liberal, la globalización puede ser interpretada como un caso de orden hegemónico en expansión, relativamente estable y prolongado. Significó, en suma, tanto la universalización del liberalismo de posguerra, como su redefinición y profundización a través de la ideología neoliberal y la transnacionalización económica, una vez libre de las ataduras de las políticas keynesianas, y de los condicionantes geopolíticos de la Guerra Fría (Sanahuja, 2017).

En una perspectiva histórica, la crisis de 2008 puede ser el hito que marque el final de ese ciclo y de ese orden hegemónico. En esa crisis se pusieron de manifiesto los límites sistémicos de un modelo de globalización altamente financierizado y carente de regulación. Pero las dinámicas económicas posteriores, más que indicar el retorno al modelo anterior, parecen anunciar una nueva fase: la que supone una revolución tecnológica ya en curso basada en la automatización, la inteligencia artificial, y las plataformas digitales, todo lo cual empieza a poner en cuestión el modelo productivo y la división internacional del trabajo en las que se basaba la globalización. También apuntan en esta dirección procesos como el ascenso de los países emergentes, que no se ajusta al tradicional patrón de multilateralismo hegemónico heredado del orden de posguerra. Como ocurrió con la 
fase de posguerra, el orden internacional de la Guerra Fría fue estable, pero no estático, y en su seno se produjeron importantes transformaciones que, a la postre, explican su final. La globalización, que ha supuesto tres décadas de transnacionalización económica y la consiguiente redistribución de capacidades productivas, significó un amplio proceso global de difusión del poder y la riqueza.

Todo lo descrito hasta ahora se ubica en el ámbito de las estructuras profundas del sistema internacional y de un cambio estructural cuyo desarrollo se observa a través de ciclos de longue durée, según los definió el historiador Fernando Braudel. De estos procesos, que aquí apenas se esbozan, se ha dado cuenta en otra parte. ${ }^{2}$ Pero no menos importantes son los factores de agencia. La definición precisa de las relaciones causales que surgen de la interacción entre agencia y estructura es objeto de una larga disputa académica, que no se aborda en estas páginas. Pero cabe observar la estrecha relación que existe entre los cambios sociales profundos generados por la globalización y su crisis a partir de 2008, el ascenso de fuerzas políticas nacionalistas y de ultraderecha, y el cuestionamiento del orden liberal en el que se ha basado la globalización.

El ascenso de estas fuerzas supone la repolitización y consiguiente contestación de normas, discursos y valores liberales que, al interior de los Estados y en el plano regional y global, antes concitaban amplios consensos en la sociedad y, por lo tanto, estaban fuera del debate político. La extrema derecha está poniendo en cuestión, desde la escena política nacional, los principios, las normas e instituciones del internacionalismo liberal contemporáneo que han sustentado el ciclo histórico de la globalización, incluyendo las organizaciones y procesos de integración regional, como la Unión Europea (UE).

No se trata solo del triunfo electoral de Donald Trump, o de Bolsonaro, del Brexit, del ascenso de la extrema derecha xenófoba en la UE, de la aparición desacomplejada de democracias iliberales que violentan el Estado de derecho en Polonia o Hungría, o de la captura y bloqueo de la política española por un enfrentamiento en clave nacionalista entre el independentismo catalán y la derecha, cada vez más escorada hacia un nacionalismo radical. Esas tendencias se extienden a los partidos tradicionales, que a menudo asumen y normalizan esas posiciones para evitar perder votos o respaldo social. Como reconoció el presidente de la Comisión Europea, Jean-Claude Juncker, en su discurso sobre el estado de la Unión de 2016, «Nunca antes había visto unos gobiernos nacionales tan debilitados por las fuerzas populistas y paralizados ante el riesgo de salir derrotados en las siguientes elecciones» (Juncker, 2016, p. 6).

2 Véase, en particular, el análisis de la crisis de la globalización como crisis de hegemonía, basado en el método neogramsciano de las estructuras históricas de Robert W. Cox, presentado en Sanahuja 2017. 
El ascenso de esas fuerzas ha sido más intenso y con mayores efectos en los países avanzados, pero el fenómeno no se limita a ellos. Distintas formas de nacionalismo se afianzan también en la Federación Rusa y en países emergentes, como Turquía, Indonesia, India o Filipinas, y alientan procesos de involución en otros países. En China, donde el nacionalismo parece haber sustituido al comunismo como ideología oficial, el clásico guion liberal que vincula de forma determinante el crecimiento y la apertura económica con el ascenso de las clases medias y el cambio político hacia la democracia y el pluralismo no se ha cumplido. Por el contrario, el país parece ir en la dirección opuesta con las reformas constitucionales de 2018, que afianzan el poder de Xi-Jinping, y la consolidación de un distópico Estado tecno-policial basado en un estricto control social. En América Latina también emerge en países con una cultura democrática afianzada, como Costa Rica, con el sorpresivo ascenso del pastor evangélico ultraconservador Fabricio Alvarado, que estuvo muy cerca del triunfo electoral en las elecciones de 2018; o en el gigante brasileño, a través del extremismo de Jair Bolsonaro, que desde una posición marginal en los primeros sondeos electorales ascendió con rapidez hasta alcanzar una amplia victoria en octubre de 2018.

Todos estos procesos presentan rasgos nacionales diferenciados, y en gran medida responden, en términos de sus factores causales, a lógicas y mediaciones nacionales. Por ello, demandan un análisis detallado y clarificación conceptual en cuanto a ideología, discursos y estrategias. Pero, más allá de las variaciones nacionales, cabe afirmar que son la expresión de una tendencia global: la triunfante expansión global de la democracia liberal y la economía de mercado que caracterizó a la pos-Guerra Fría y alimentó el optimismo del fin de la historia, según la expresión de Francis Fukuyama (1992), parece haber terminado y la tendencia ahora tiene el signo contrario. Países que contaban con democracias consolidadas, o en proceso de consolidación, ahora están gobernados por líderes nacionalistas y populistas de derecha o ultraderecha que ponen en cuestión el pluralismo político y social, el Estado de derecho, las garantías propias de los regímenes democráticos, y otros elementos característicos de las sociedades abiertas, que promueven además discursos contrarios a la globalización y a la inmigración, securitarios y defensivos, y distintas expresiones del nacionalismo e incluso del nativismo. Se empieza a asumir, incluso, la compatibilidad del libre mercado con modelos políticos autoritarios o con democracias iliberales, como ya ocurrió en América Latina en los años setenta.

Si el final de la Guerra Fría fue parte de la tercera ola de la democracia, tras la crisis de 2008 se estaría asistiendo a una oleada antiliberal y nacionalista impulsada por el ascenso, a escala global, de la extrema derecha y el nacionalismo extremo. Su efecto disruptivo tanto en los sistemas políticos y de partidos 
nacionales como en el sistema político internacional podrían interpretarse como indicadores de lo que en las categorías neogramscianas se denomina crisis orgánica derivada tanto de transformaciones económicas, como del debilitamiento de los consensos y los mecanismos de dominación por consentimiento del bloque histórico imperante.

\section{Fuerzas sociales en cambio y orden internacional}

Como ha afirmado John Ikenberry, el orden liberal no se está viendo cuestionado solo ni principalmente por una crisis E. H. Carr - es decir, en clave de multipolaridad, juego geopolítico y supuestos dilemas de Tucídides entre grandes potencias - sino por una crisis K. Polanyi, relacionada más con una gran transformación que afecta a sus bases económicas y sociales, y las asunciones colectivas sobre democracia social, y que por ello pone en cuestión la legitimidad del sistema (Ikenberry, 2018, p. 10). Se trataría de un desplazamiento del poder del trabajo hacia el capital, con la anuencia e incluso la activa colaboración de los Estados, que como se indicará estaría en el origen de la reacción popular y populista en alza en muchos lugares. Además del fracaso de sus supuestos de autoregulación, para muchos colectivos la globalización también ha incumplido sus promesas de inclusión social, al generar brechas sociales crecientes y al tiempo, debilitar la capacidad estatal para atenderlas, y generar miedo e incertidumbre ante cambios y amenazas que ni el Estado ni las élites tradicionales parecen capaces de conjurar.

Tanto en los países en desarrollo como en los emergentes y los avanzados se evidencia, con pocas excepciones, un marcado aumento de la desigualdad asociado a la globalización, que en algunos casos se acelera con la crisis económica iniciada en 2008. En los países avanzados, incluso allí donde las tasas de desempleo son bajas, se erosionan los pactos sociales nacionales, la estructura del empleo se torna más dual entre los sectores de bajos ingresos y ocupaciones más precarias, y aquellos, más calificados y protegidos, cuyas rentas aumentan o sufren en menor medida las presiones competitivas mencionadas. En conjunto, aumenta la inseguridad laboral respecto a la capacidad de protección del Estado. En los países emergentes, por el contrario, se produce un rápido aumento de las expectativas de ascenso social y de las demandas hacia el Estado, las formas de gobierno y sus políticas públicas. Aunque es un proceso en el que existen muchas e importantes variaciones nacionales, los procesos de globalización y transnacionalización, en conjunto, constriñen fuertemente la agencia de los Estados territoriales y de sus élites tradicionales para desarrollar políticas autónomas o desplegar los supuestos recursos de poder que su respectiva estatura económica pareciera otorgarles. Ello 
limita la capacidad de las políticas públicas para materializar las aspiraciones, demandas y derechos de las sociedades, en la medida que aún se definen a través de procesos políticos de alcance eminentemente nacional.

La crisis de gobernanza y las dificultades de los Estados y en particular de las democracias occidentales para hacer frente a las brechas sociales y la incertidumbre generadas por la globalización han tenido efectos múltiples. Hay que subrayar que el orden liberal de posguerra no se limitó a un conjunto de principios y normas internacionales, sino que hunde sus raíces en una concepción de democracia social que, fundada en el ciclo productivo fordista, integró a los trabajadores, el Estado y el capital en lo que puede entenderse como un amplio pacto social y corporativo tripartito. De acuerdo con la conceptualización de Cox (1981) o de Gill (1995, 2008), se trata de una particular forma de Estado contingente a esa estructura histórica, que suponía un modelo de democracia social que reconocía amplios derechos sociales y laborales, establecía mecanismos avanzados de protección, e institucionalizaba tanto la participación laboral en la gestión económica, a través de la negociación colectiva, como en el sistema político, a través de partidos obreros y sindicatos de amplia base (Sanahuja, 2015).

A cambio, ello otorgó la necesaria legitimidad y atractivo a las democracias occidentales frente al bloque soviético, aseguró la lealtad de los trabajadores y sus organizaciones políticas y sindicales, orientadas a la socialdemocracia o el eurocomunismo. Como señaló Tony Judt (2005, p. 544), la clase obrera, en parte subsumida en una clase media de amplio espectro, tuvo por primera vez un interés material: el sostenimiento y consolidación del Estado social y democrático de derecho, a diferencia de lo ocurrido en el período de entreguerras. Con ello, la estabilidad y la paz social en el ámbito nacional se entrelazaba con las lógicas de seguridad internacional de la Guerra Fría (Hobsbawn, 1995; Jayasuriya, 2010). En suma, estos pactos sociales y el modelo corporativo de relaciones laborales eran funcionales al modelo productivo fordista de dos maneras: por un lado, evitaron la reaparición de las cíclicas crisis de sobreproducción o de subdemanda que habían contribuido, por ejemplo, a la Gran Depresión de los años treinta. Por otro, garantizaron la estabilidad política y la paz social que Occidente requería para enfrentarse al bloque comunista. Como señaló Eric Hobsbawn (1995, p. 278), el miedo al comunismo también jugó un papel decisivo, pues estos pactos sociales permitieron integrar en el sistema, en una lógica corporativa, a los trabajadores y a sus organizaciones, que se adscribieron a la socialdemocracia o al eurocomunismo.

Este modelo corporativo tripartito, que integraba al Estado, al capital y al trabajo, se desarrolló plenamente en los países avanzados de Occidente, pero las políticas nacionalistas y desarrollistas del periodo poscolonial, a menudo respaldadas por mecanismos financieros, comerciales y de ayuda económica y militar de Estados Unidos 
y sus aliados occidentales, significaron en algunos casos una notable ampliación de la ciudadanía y fórmulas inéditas de democracia social — en otros casos fue al contrario, con distintas fórmulas de modernización autoritaria, incluso regímenes dictatoriales-, que contribuyeron a su alineamiento con el bloque occidental.

En términos de cambio estructural, el fin de la Guerra Fría hizo desaparecer algunos de los factores geopolíticos en los que se basó el orden internacional liberal y alentaban la continuidad de esos mecanismos de vinculación de los trabajadores con las democracias occidentales. En paralelo, las dinámicas económicas de la globalización han supuesto una fuerte erosión de ese modelo de democracia social, debilitado por procesos de transnacionalización productiva y de liberalización de los mercados en los que el Estado dejó de asumir ese rol protector. Como señala acertadamente John Ikenberry (2018), la tercera ola democrática de los noventa, a la vez causa y consecuencia del colapso del bloque soviético, supuso la expansión global de los derechos políticos, pero al estar vinculada al neoliberalismo económico también significó mayor desigualdad, crisis fiscal y una marcada erosión del componente económico y social de la ciudadanía, tanto en los países avanzados como en aquellos países en desarrollo que habían establecido diversos modelos de pacto social. La recurrente crisis de legitimidad que ha acompañado a esa ola democratizadora es el resultado directo de esa contradicción.

Ello explicaría distintos ciclos de contestación como el que atravesó América Latina al inicio de los 2000, con el ascenso de fuerzas progresistas y en particular de las autodenominadas bolivarianas. Estas articularon la respuesta social y política frente a una crisis de la región, entre 1998 y 2003, percibida como consecuencia de la globalización neoliberal. También sería el caso del ciclo de contestación en los países avanzados desde la crisis de 2008, que también generó un descontento social de amplio espectro, especialmente en los sectores más desprotegidos frente a la globalización. Ante esos factores, que cabría ubicar en la estructura, surgen nuevos actores - verdaderos entrepreneurs políticos-que han sabido sacar partido de ese descontento, ante la pasividad o indolencia de las élites y las fuerzas políticas tradicionales - de nuevo, factores de agencia- y con ello han impulsado el ascenso de nuevas o renovadas fuerzas de extrema derecha. En uno y otro caso estas fuerzas se nutren del descontento social con la globalización y sus efectos - factores de estructura-, aunque las expresiones políticas de contestación sean distintas y se hayan ubicado en distintos lugares del espectro político, e incluso en posiciones opuestas. 


\section{Contestación y repolitización: el orden internacional liberal en cuestión}

El más reciente ciclo de contestación en los países avanzados se ha descrito e interpretado como expresión del retorno de la política y de la repolitización de cuestiones hasta entonces objeto de consenso dentro del orden internacional liberal (Zürn, 2014; Grande y Hutter, 2016), como el libre comercio, los derechos humanos, o la integración europea (Grande y Kriesi, 2012; Höglinger, 2016), así como la politización de cuestiones como las migraciones, que de esa manera adquieren una prominencia política mucho mayor que en el pasado. Con ello, llega a su fin, o entra en una profunda crisis el hasta ahora apenas cuestionado reinado tecnocrático del liberalismo y el neoliberalismo, fuera en su versión de centroderecha o socialdemócrata, en el que el espacio de lo político se reducía a la confrontación electoral en torno a cuestiones que no suponían la impugnación de ese orden (Zürn, 2014; Pelfini, 2017). La crisis de 2008, unida a otros riesgos de la globalización, suponen incertidumbre y miedo a un futuro que se percibe como amenaza, tanto para las generaciones presentes (pensiones) como para las futuras (empleo y precariedad), y la gestión liberal y tecnocrática de la globalización no parece capaz de conjurar esa incertidumbre, ni de ofrecer garantías creíbles de protección de la sociedad ante contingencias y riesgos globales (Zürn y De Wilde, 2016; Pelfini, 2017, p. 61). Se hunde así la credibilidad de las narrativas de progreso de la pos-Guerra Fría y la globalización, tanto en la versión cosmopolita de la socialdemocracia, que se muestra irrelevante o inaplicable, como en la variante neoliberal, más arrogante e insensible a la desazón de las clases medias y bajas, e igualmente ineficaz (Garcés, 2017, p. 16).

Este proceso de politización, contestación y crisis de consensos dominantes ha sido en muchos casos abordado desde explicaciones centradas en la agencia, y en particular, en la irrupción de nuevos actores políticos y en la forma en la que constituyen, orientan o aprovechan el impulso de las preferencias de los votantes o de distintos grupos sociales (Dolezal, 2012; Grande, Schwarzbözl, Fatke, 2018). De manera general, politización significa que las decisiones colectivas vinculantes se tornan en objeto de discusión pública, pudiendo llegar a definir nuevas divisorias o clivajes políticos. Para Zürn (2014, p. 50), se trata del proceso por medio del cual los poderes que toman decisiones y las interpretaciones de los hechos y las circunstancias asociadas a estas son llevados a la esfera política, sea al subsistema político, o al espacio político, siendo este último aquel en el que existe comunicación pública, toma de conciencia, movilización y contestación de las decisiones colectivas vinculantes referidas al bien común. 
Generalmente, esos procesos han tenido lugar en las arenas políticas nacionales, salvo en circunstancias extraordinarias, como la guerra. El elemento nuevo que ha traído la globalización sería la politización por parte de los actores políticos domésticos, y en la arena política nacional, de las normas e instituciones internacionales. Ello comporta el debate público y la impugnación de decisiones, normas e instituciones que antes se formulaban en espacios tecnocráticos o burocráticos ajenos a la esfera pública, con una notable influencia de intereses privados del capital transnacional. De manera más específica, las variaciones en cuanto a la politización de las organizaciones internacionales dependerían de un mayor ejercicio de su autoridad y la legitimidad que ostentan (Zürn, 2014, p. 48). En gran medida, este proceso fue iniciado en los años noventa por los actores y coaliciones altermundialistas que convergerían posteriormente en el Foro Social Mundial de Porto Alegre, y parte de la literatura sobre la actuación de estos actores interpretó ese proceso de politización de las instituciones y normas internacionales en las que descansaba la globalización en términos de reacción democratizadora a la reducción del papel, la autonomía y la soberanía de los Estados nación, en términos, como se señaló en secciones anteriores, de resistencias a la globalización, o de la emergencia de un nuevo multilateralismo cosmopolita o contrahegemónico desde abajo. Pero como señaló Zürn (2014, p. 64), en esa aproximación se obvió o se subestimó otro fenómeno posterior que no encajaba con esas movilizaciones transnacionales: la posibilidad de una politización anticosmopolita, nacionalista, y de ultraderecha, que encauzó el malestar de los perdedores de la globalización, fuera en términos de empleos, ingresos, estatus y expectativas, o de conflictos socioculturales.

Sin embargo, la interpretación de ese proceso de politización y contestación, centrada en los actores y, en particular, en la transferencia de autoridad a las organizaciones internacionales, obviaría otras posibles explicaciones centradas en los cambios de las estructuras económicas y sociales más profundas. En realidad, puede alegarse que la pérdida de autoridad y capacidad de protección de los Estados nación y las políticas estatales no se debe en muchos casos a que sus competencias hayan sido atribuidas o transferidas a las instituciones internacionales hacia las que entonces se dirigirían los reclamos de la ciudadanía. En realidad, las organizaciones internacionales —incluyendo la UE - se muestran igualmente impotentes y son parte de la matriz de política estatal que se ha extendido con la globalización: aquella que, como señaló Rodrik (2011) en su conocido trilema o trinidad imposible de la globalización, trataría de mantener una globalización profunda y el Estado nación como locus de la política. Ello significa situar la acción estatal en la camisa de fuerza dorada de la globalización, en la que la única política económica y de desarrollo posible es aquella que se ajusta a los requerimientos de un mercado global altamente financierizado. Es decir, significa 
sacrificar el tercer elemento de ese trilema: la democracia, tanto en su dimensión electoral, como en su contenido substantivo de democracia social vinculada a un amplio catálogo de derechos económicos y sociales. Es el caso de la UE, en particular: es difícil que ese proyecto pueda perdurar si termina siendo un remedo del peor FMI, imponiendo en nombre de la austeridad expansiva ajustes impopulares cuyo coste social anima el ascenso de fuerzas antieuropeas. La UE podrá dominar, pero no convencer, si deja de ser un proyecto autónomo frente a la globalización; si se convierte en poco más que un instrumento de la disciplina de los mercados, encargado de velar por la estabilidad macroeconómica y, por ello, con un grave déficit democrático, en términos de su tradicional legitimidad de resultado ligada a la generación de bienestar económico y ciudadanía social, y una fuerte crisis de su identidad como modelo de progreso (Sanahuja, 2012, p. 63).

Ese diagnóstico no difiere mucho de la definición del Estado neoliberal de Cox o Gill, que se configura como nueva forma de Estado en la globalización, y de lo que plantea el método de las estructuras históricas. Por ello, sin que exista ninguna predeterminación previa en cuanto a lógicas de causalidad, ese ciclo de repolitización y contestación sería más bien la expresión de la crisis de la globalización como modelo o proyecto hegemónico de orden, tanto en lo referido a su dimensión societal, como en la manera en la que se expresa en el ámbito internacional, a través de las instituciones y normas que rigen los mercados regionales y globales, y las relaciones interestatales.

Por ello, como ya se ha afirmado, en ese escenario de crisis de globalización acontecimientos como el Brexit o el triunfo electoral de Donald Trump no pueden ser considerados como meros cisnes negros más o menos impredecibles, en el sentido que da a esta expresión Nassim Taleb (2010). Son resultado de factores de agencia - la capacidad de articular discursos y narrativas movilizadoras en los medios de comunicación o en las redes sociales, o el éxito de una campaña electoral—, de actores que protagonizan ese nuevo ciclo de politización y contestación del orden internacional liberal y de la globalización, pero no se explicarían sin otros factores causales de carácter estructural relacionados con el impacto social y cultural de la globalización en cuanto a debilitamiento del Estado y de su capacidad para la protección de la ciudadanía y para el mantenimiento de sus expectativas de bienestar, y sus derechos económicos y sociales.

En términos de agencia, el descontento social que genera la crisis de la globalización deviene así en crisis de legitimidad de la democracia liberal, que supone un amplio cuestionamiento de las élites y del establishment favorable a la globalización. De esa crisis se nutre el ascenso de nuevos actores de extrema derecha, líderes fuertes, la política del miedo y el rechazo creciente a las sociedades abiertas. Ese proceso, que expresa una crisis de hegemonía de dichas élites, de nuevo 
tiene afectos tanto al interior de cada Estado como en el plano internacional. La impugnación de las élites y la crisis de legitimidad de las democracias debilitan, a su vez, el liderazgo y la posición hegemónica que había mantenido el conjunto de los países avanzados —en particular Estados Unidos y la UE- en el sostenimiento del orden internacional liberal o, en otros términos, en lo que podría interpretarse como el blocco storico en el que se ha basado la globalización.

\section{Dinámicas socioeconómicas y reacción sociocultural: factores causales}

Entre las causas de ese ascenso, como se indicó, son factores estructurales las dinámicas de cambio social impulsadas por la globalización y el cambio que ello comporta en las expectativas de distintos grupos sociales, en particular de las clases medias; y en cuanto a la agencia, hay que destacar el papel de los nuevos actores políticos en juego, que son extraños a las élites y el establishment tradicional, o habiendo sido parte de estas, se perciben como ajenos a ellas. En un detallado análisis sobre las causas del auge de la extrema derecha, Inglehart y Norris (2016) categorizan como fuerzas motrices del lado de la demanda (demand-side drivers) esas causas estructurales. En el lado de la oferta (supply-side drivers) se situarían la actuación, narrativas y líderes de la constelación emergente de partidos y líderes de extrema derecha. Se examinarán brevemente unos y otros factores causales e impulsores del ascenso de la ultraderecha.

En términos de cambio social, como se indicó, la globalización ha sido un fenómeno de vastas proporciones, comparable quizás a la primera revolución industrial, o al advenimiento del fordismo como ciclo productivo tras la Segunda Guerra Mundial. Si bien la globalización ha tenido una capacidad notable en la reducción de la pobreza y la inclusión social de los sectores medios citados, también ha generado mayor desigualdad global, y dinámicas de exclusión y segmentación social que han afectado a otros grupos. Como señalan Milanovic (2012, 2016) y Lakner y Milanovic (2016), en ese proceso, en términos de reducción de la pobreza y distribución del ingreso cabe identificar claros ganadores y perdedores: pierde el bottom billion, los en torno a mil millones de personas estancadas en la pobreza extrema y el hambre, en su mayoría en África subsahariana y Asia meridional, y las clases medias y los trabajadores de menor cualificación de los países avanzados, que experimentan en mayor medida las consecuencias de un mercado de trabajo cada vez más dual, con un horizonte de desempleo, precariedad laboral, recorte de derechos e incertidumbre asociada al cambio tecnológico. Ganan las clases medias en ascenso de los países emergentes, que han dejado 
atrás la pobreza y pueden acceder al mercado de consumo, y la estrecha capa de la población más rica, tanto en los países emergentes, como en los avanzados.

Estas brechas globales entre ganadores y perdedores son una variable cada vez más relevantes para explicar las diferencias de renta nacionales, y para la conformación y la satisfacción o no de las expectativas individuales y colectivas. Expectativas en ascenso en los países emergentes, que alimentan tanto respuestas individuales - mayor presión migratoria hacia los países ricos-, como colectivas, a través de movimientos sociales que, desde América Latina al mundo árabe, reclaman mejor gobernanza y políticas públicas más eficaces e inclusivas. Y en los países avanzados, el rechazo a expectativas en descenso, en un contexto de recorte de derechos sociales y creciente inseguridad y precariedad laboral.

En 2013, las encuestas del Pew Global Research Center (2014) mostraban esa brecha: en los países emergentes, la mayor parte de la población afirmaba que la siguiente generación viviría mejor que la de sus padres, pero en los países avanzados la mayoría esperaba lo contrario. El Eurobarómetro de 2018 también muestra que en el conjunto de la UE el $54 \%$ de la población consideraba que la sociedad se había tornado menos igualitaria que treinta años antes, y el $84 \%$ que el nivel de desigualdad socioeconómica era excesivo (Comisión Europa 2018). Las encuestas globales de Ipsos-MORI, aunque más sensibles a cambios de corto plazo, también muestran que existe una divisoria global del optimismo, en las que las sociedades de la mayor parte de los países emergentes se muestran mucho más esperanzadas que las de los países avanzados, que ven el futuro con aprensión e incertidumbre (Atkinson, 2017, pp. 53-59). Esas encuestas muestran que la mayoría de la población mundial piensa que su país no va en la dirección correcta - $61 \%$ en 2016 y $58 \%$ en 2018 - , pero esa percepción es más marcada en el conjunto de los países avanzados, y en algunos países emergentes, como Brasil o México, mientras que los casos de India y China la proporción de los optimistas llega al $65 \%$ y al $94 \%$ respectivamente (Ipsos 2016, 2018).

Los indicadores globales de bienestar suponen transformaciones estructurales de largo plazo y parecen apuntar a un cambio en el ciclo histórico de longue durée, más que al impacto coyuntural del ciclo económico o la crisis financiera, y ello parece marcar los límites sociales de la globalización. Serían equiparables a las que han marcado los grandes cambios sociales que se pueden observar desde el tránsito del Antiguo Régimen a la Revolución Industrial. En el periodo previo a la industrialización, la diferencia entre la renta promedio de los diez países más ricos y los diez más pobres era de unas seis veces. Esa brecha, relativamente pequeña, coexistía con enormes desigualdades al interior de cada país entre una élite terrateniente y las masas campesinas. La revolución industrial significó un 
proceso de aumento simultáneo de la desigualdad entre países —en un rápido distanciamiento de Europa y Estados Unidos del resto del mundo-, y al interior de los países, con brutales diferencias entre la burguesía y el nuevo proletariado fabril. Al menos durante un siglo de industrialización se confirmó la clásica hipótesis de Simón Kuznets - representada a través de una curva en forma de U invertida-, que planteaba que en las fases tempranas de la industrialización la desigualdad aumentaba en la medida que se producía el (necesario) proceso de acumulación y reinversión de capital en manos de la burguesía industrial y financiera, cuyo mayor exponente pudieran ser los magnates de la edad de oro del capitalismo, altamente oligopolizado, de finales del siglo XIX y principios del $\mathrm{xx}$ en los Estados Unidos, con representantes como los Vanderbilt, Rotschild, Carnegie, Mellon, Morgan, o Rockefeller.

La revolución industrial, empero, hizo aparecer un potente movimiento obrero que obligó a introducir desde finales del siglo XIX nuevas leyes laborales, incipientes sistemas de salud pública y seguridad social, una fiscalidad más progresiva, y leyes antimonopolio. El alcance de estas medidas se amplió en el siglo $\mathrm{xx}$, como respuesta de las democracias liberales a las amenazas del fascismo y el comunismo, y en parte como compensación por los enormes esfuerzos impuestos a los trabajadores, verdadera carne de cañón en la Primera y Segunda Guerra Mundial. Podría decirse que el alcance del reformismo de posguerra y la democracia social adoptada en los países avanzados y en particular en Europa occidental fue tal, que dejó al capitalismo irreconocible respecto a sus versiones de entreguerras (Hobsbawn, 1995, p. 275).

Después de 1945, el espectacular aumento de la productividad generado por el modelo industrial fordista y las políticas de demanda keynesianas propiciaron nuevos pactos sociales basados en la expansión de las rentas salariales y del Estado del bienestar y la protección social. Ello contribuyó decisivamente a la formación de las sociedades de clases medias en el Occidente industrializado, en un círculo virtuoso que relacionaba consumo de masas, crecimiento económico y equidad social, tanto en lo referido a la distribución del ingreso como a una mayor movilidad social, y a la vez permitió integrar a los trabajadores y sus organizaciones en un modelo de democracia social más atractivo que el existente tras el telón de acero.

Como se indicó, hubo también un grupo de nuevos países industrializados (NIC) que lograron aunar dinamismo económico y equidad social, y algo similar se observó en las experiencias de industrialización tardía de algunos países mediterráneos. En otros países en desarrollo se intentó adaptar este modelo a sus condiciones periféricas a través de acuerdos nacional-populares y políticas desarrollistas. Si bien propiciaron la aparición de nuevas clases medias urbanas, estas experiencias de desarrollo no lograron quebrar los condicionantes de las 
economías primario-exportadoras, y en muchos casos dieron lugar a modelos de crecimiento concentrador y excluyente, que mantuvieron e incluso agravaron las brechas sociales del orden poscolonial.

Este ciclo tuvo dos claras consecuencias en términos de desigualdad. En Estados Unidos, como en otros países industrializados, se produjo lo que Goldin y Margo (1992) denominaron la gran compresión, por oposición a la Gran Depresión (Noah, 2012): desde los años cuarenta - los cincuenta en Europa - las rentas de las clases bajas y medias aumentaron más rápido que las correspondientes a las capas más altas y en los años setenta se registraron los indicadores más favorables en materia de equidad en un período de cincuenta años. Sin embargo, con la excepción de los NIC, la brecha internacional se agrandó y la diferencia entre la renta per cápita promedio entre los diez países más ricos y los diez más pobres llego a ser de cuarenta veces (Bourguignon y Morrison, 2002; Bourguignon, 2012).

A la luz de este rápido recorrido por los dos últimos siglos, lo que revelan los datos expuestos en la sección anterior es un giro de proporciones históricas en ambas tendencias: aunque continuó empeorando la desigualdad internacional entre Norte y Sur, entre 1945 y mediados de los años setenta del siglo xx se registraron al interior de los países avanzados los mejores indicadores en materia de equidad en los doscientos años que median entre la revolución industrial y los primeros años del siglo XxI. Ello fue posible a causa, tanto del extraordinario ciclo de crecimiento económico impulsado por el fordismo, como de los pactos sociales que se sustentaron en el aumento de la producción y la productividad que ese ciclo hizo posible. Como señaló el historiador Eric Hobsbawn, el período 1947-1973 no solo representa una edad de oro para el capitalismo en términos de crecimiento y estabilidad económica — Les trente glorieuses, según Jean Fourastié (1979)—; es también un período en el que durante algunas décadas, a mediados de siglo, pareció incluso que se había encontrado la manera de distribuir dentro de los países más ricos una parte de la enorme riqueza generada en ese período, con un cierto sentimiento de justicia (Hobsbawn, 1995, pp. 18, 22).

Desde mediados de los ochenta, sin embargo, la globalización significó un visible cambio de ciclo: por primera vez en unos cien años, la brecha entre los países ricos y los países en desarrollo - al menos los emergentes - empezó a estrecharse, pero también comienza lo que Paul Krugman (2007, pp. 124-128) llama la gran divergencia: la desigualdad interna tanto en los países avanzados como en desarrollo, con algunas excepciones, experimentó un fuerte aumento (OCDE, 2008, 2011 y 2015; Sanahuja, 2013).

A la hora de explicar que las diferencias entre países se reduzcan, como que aumenten en su interior, hay que remitirse de nuevo a la gran transformación, 
por utilizar la expresión de Karl Polanyi (1992), que a través de la globalización ha sacudido a la economía mundial desde los años ochenta. La globalización ha supuesto un notable aumento de la escala y el tamaño de los mercados, y mayores presiones competitivas, que suponen una creciente disparidad de ingresos en unos mercados de trabajo en rápida transformación hacia una estructura dual: con mayores retribuciones para los trabajadores de la economía del conocimiento, y caída de las retribuciones y el número y calidad de los empleos de naturaleza administrativa y manufacturera antes asociados a las clases medias.

Por otro lado, la incorporación a la economía mundial, en muy pocos años, de más de 1500 millones de trabajadores de los países emergentes ha incrementado la tasa de ganancia del capital transnacional, y golpea a la población trabajadora con menor cualificación de los países avanzados, sometiéndoles a la competencia global sin que ya pueda protegerles la regulación estatal. La bibliografía sobre esta cuestión destaca cómo el cambio tecnológico y las brechas de cualificación, en un contexto de apertura y globalización, juega un papel determinante en el aumento de la desigualdad. Los procesos de financierización que han caracterizado a la fase más tardía de la globalización también han jugado un papel relevante, como destacó Thomas Piketty (2014) al señalar la tendencia a una mayor tasa de crecimiento de las rentas del capital, que la de la economía en su conjunto - lo que resume con la fórmula $\mathrm{r}>\mathrm{g}$ - como uno de los vectores que impulsan una desigualdad que de manera creciente se explica por la mayor concentración de la riqueza mundial en quienes poseen más capital financiero. Finalmente, hay que mencionar la tendencia, propiciada por un mercado global más integrado y el cambio tecnológico, a la concentración del capital, la oligopolización de los mercados, y un modelo centrado en la extracción de rentas monopólicas, que es particularmente visible en las nuevas compañías tecnológicas de alcance global.

Pero no menos importante es la erosión de las instituciones que promovieron la equidad en el pasado, como la negociación colectiva, la fiscalidad progresiva y las políticas sociales, atrapadas en los confines del Estado nación y los pactos sociales nacionales, que se debilitan cuando la competencia y los mercados son ya globales. Estos procesos, además, han sido acelerados por la crisis económica, que ha supuesto mayor desempleo y recortes sociales, como revela el aumento de las brechas salariales y de la desigualdad visibles en las estadísticas internacionales, y a futuro, dudas respecto a la sostenibilidad del Estado del bienestar, y los derechos económicos y sociales, menores expectativas de movilidad social ascendente que las que presuponen las sociedades abiertas, y más incertidumbre e inseguridad laboral. Surge un nuevo precariado sin expectativas, particularmente para los desempleados de larga duración y los jóvenes, para quienes tiene poco que ofrecer que el actual statu quo y las tendencias hacia la uberización del 
empleo y una gig economy o economía de los bolos o del trabajo esporádico, de falsos autónomos o cuentapropistas, siempre disponibles, con encargos esporádicos a través de una plataforma electrónica, atomizados y sin protección social.

Sería ilusorio suponer que estas transformaciones no tienen implicaciones políticas. Dani Rodrik (2011), como antes se mencionó, ha señalado que en el contexto de la globalización los actores estatales enfrentan un trilema irresoluble, en el que la globalización económica profunda, el Estado nación y la política democrática son tres objetivos que no pueden ser satisfechos simultáneamente, y que las únicas políticas posibles combinarían dos de ellos. Desde la Segunda Guerra Mundial, al no existir una integración económica global profunda, el Estado nación y la política democrática fueron compatibles y viables, mediante lo que Rodrik denomina compromisos de Bretton Woods. Es el período en el que fueron posibles los pactos sociales de posguerra y las políticas económicas keynesianas, a partir de un modelo de producción fordista orientado al pleno empleo, el consumo de masas y el desarrollo de los Estados de bienestar.

Ya se ha señalado como ese modelo, tras la crisis de los setenta, dio paso a procesos de apertura y liberalización económica que iniciaron la globalización. Las crisis financieras de los años noventa en adelante pusieron de manifiesto que en condiciones de globalización profunda y Estados nación como locus del poder político, su agencia se debilita, y solo parece posible gobernar en función de las exigencias del mercado global postergando mandatos electorales relacionados con derechos sociales. A partir de 2008, la crisis financiera global actualizó la vigencia de este trilema, especialmente en la zona euro - con la unión monetaria al trilema es mucho más rígido, al no estar disponibles los instrumentos de la política monetaria - y en particular, en los países que, afectados por crisis de deuda soberana, fueron sometidos a duros programas de ajuste tutelados por la troika. Ello indicaría de nuevo que, como orden mundial, la globalización supone un modelo de gobernanza basado en la adaptación de los Estados — sus estructuras económicas, políticas y sociales; sus instituciones, y sus pactos sociales nacionales - a los requerimientos del mercado globalizado. Sería una nueva forma de Estado neoliberal, muy distinto al del período del fordismo (Cox, 1981). Se producirá, en particular, una amplia constitucionalización externa de las reglas que gobiernan los mercados, fuera del alcance de las políticas y actores nacionales (Gill, 1995), a través de las reglas de la OMC y, en mucha mayor medida, mediante la firma de acuerdos regionales de libre comercio y de los relativos a la protección recíproca de inversiones, en una forma de proyección global del ordoliberaliamo, que Quinn Slobodian $(2018$, pp. 12, 266) denominara ordoglobalismo.

Los datos empíricos referidos al apoyo a la extrema derecha muestran, de manera consistente, el apoyo de sectores que por edad, sexo, nivel educativo o 
lugar de residencia son o bien perdedores de la globalización o se perciben como tales, o rechazan los procesos de cambio sociocultural y mayor diversidad social que se asocian a la apertura y a la globalización. En términos socioeconómicos, han sido los trabajadores manufactureros cualificados en Europa o en Estados Unidos los que en mayor medida han experimentado o bien el cierre de empresas por efecto de la deslocalización, o bien la pérdida de capacidad negociadora y el estancamiento de los salarios ante la amenaza de cierre. Los trabajadores de baja calificación en sectores de bienes no transables - hostelería, servicio doméstico, agricultura, construcción...-y, por lo tanto, no susceptibles de ser deslocalizados también se consideran perdedores de la globalización, en tanto su salarios y estabilidad laboral se ven erosionados por la inmigración, y se tornan más críticos hacia ese proceso. De nuevo, como tendencia general, los sectores medios ligados a los servicios, los trabajadores con mayor calificación, y aquellos que disfrutan de empleos más estables y protegidos - funcionarios públicos, profesiones liberales que se protegen a través de reglas y de colegios profesionales...- han sufrido menos los efectos de la globalización y tienden a tener una percepción más positiva y su actitud suele ser más abierta y cosmopolita ante ese fenómeno (The Economist, 2018a).

De hecho, la explicación socioeconómica, aunque contiene factores causales clave, no bastaría para explicar el fuerte ascenso de esas fuerzas. Höglinger, Wüest y Helblig (2012) destacan como los debates sobre la globalización no se limitan a las dimensiones socioeconómicas y también incluyen pugnas sobre aspectos socioculturales a través de una serie de enmarcados-tipo preferidos por los distintos actores políticos. Como se mencionó, Inglehart y Norris (2016), a partir de encuestas realizadas en 31 países, argumentan que otro importante factor estructural es un movimiento sociocultural reaccionario (cultural backlash), especialmente en las generaciones de mayor edad, los hombres blancos y los sectores menos calificados, antes dominantes, y que se resisten a perder su estatus frente al avance de la diversidad cultural y de los valores cosmopolitas de las sociedades abiertas y de la globalización. Esos grupos serían particularmente vulnerables al llamado de los populistas de derechas.

En el caso de países más tradicionalistas, se generan resistencias de los sectores tradicionales ante el ascenso socioeconómico de las clases subalternas - caso, por ejemplo, de Brasil (Natanson, 2018) - o la pérdida de estatus de las clases medias tradicionales, así como ante el cambio sociocultural hacia sociedades más igualitarias, abiertas y tolerantes con las cuestiones de género e identidad sexual, las minorías o la diversidad social, que amenazan los roles, conductas y valores tradicionales. Resistencias que la extrema derecha se ha apresurado a explotar cuestionando las políticas de inclusión social, lo que denominan la ideología de 
género, el matrimonio igualitario, el aborto, o la educación sexual en las escuelas. Este sería el caso de algunos países de Europa central, en las que el apoyo a la extrema derecha está claramente asociado a posiciones más tradicionales en esos asuntos, en materia de religión, y se observa también un mayor nacionalismo cultural y un rechazo mayor a la población musulmana pese a que su presencia es mucho menor que en otros países de Europa Occidental (Pew Research Center, 2018). También sería el caso de las elecciones en Costa Rica o en Brasil en 2018, país en el que a ese factor se le suma un reclamo securitario de corte punitivista, en palabras de José Natanson (2018).

Ahora bien, como señalan Norris e Inglehart la distinción analítica entre factores socioeconómicos y la reacción cultural es artificial, pues ambos están relacionados:

[...] si los cambios estructurales en la fuerza de trabajo y las tendencias sociales en los mercados globalizados elevan la inseguridad económica, y si esto, a su vez, estimula una reacción negativa entre los tradicionalistas hacia los cambios culturales, no sería una cuestión de si es lo uno o lo otro, sino del peso relativo de ambos y de los efectos de su interacción. (Inglehart y Norris, 2016, p. 3).

La divisoria generacional, por ejemplo, es clave: las personas entre 18 y 44 años se muestran más proclives a la apertura y al cambio, pero las mayores de 45 son más reacias a aceptar la diversidad social y cultural, rechazan el cambio al asumir que no pueden adaptarse a sus exigencias (Marshall, 2017, pp. 35-37), y son más sensibles a las cuestiones sobre inmigración, ley y orden, derechos de las minorías y de las mujeres, o diversidad sexual (Khan, 2017, p. 41; The Economist, 2018a). En suma, ambos conjuntos de factores serían necesarios para explicar el creciente malestar social y la desafección ciudadana hacia la democracia y los partidos tradicionales, que los nuevos actores de la derecha populista y xenófoba han sabido movilizar y canalizar para ganar peso electoral, poder parlamentario, y hacerse con el gobierno de algunos países. 


\section{Factores de agencia: líderes, discursos, retórica, redes y comunicación}

Más allá de los cambios estructurales, para entender la pérdida de influencia de las élites dominantes y el declive electoral de los partidos tradicionales es necesario examinar los factores de agencia, y en particular, la actuación de una pléyade de partidos y líderes de extrema derecha nacionalista y xenófoba, y lo que ofrecen y cómo lo enmarcan, con estrategias y discursos de deslegitimación y de polarización que cabría calificar como insurgentes (Dennison y Pardijs, 2016). Aunque algunos de los partidos de derecha radical estaban ya activos en los años ochenta, se trata de movimientos que o bien se han redefinido y reposicionado a partir de la crisis, o en muchos casos son de reciente aparición. En su mayoría están desconectados de los fascismos del siglo xx y no responden a esa caracterización, a menudo utilizada por sus oponentes, y en muy pocos casos han tenido experiencia de gobierno.

Como ha definido Hanspeter Kriesi (2012a, p. 108) o Martin Dolezal (2012, p. 134), en el ascenso de estas fuerzas hay que destacar la actuación de verdaderos emprendedores políticos que actúan a través de una lógica en la que cabría identificar tres pasos: el posicionamiento político; la selección o construcción de las agendas, a través de cuestiones que se caracterizan por su visibilidad y prominencia; y la movilización política a través de la polarización social en torno a esas cuestiones. Para ello, estos actores han sabido generar y difundir potentes narrativas o discursos de movilización y polarización para la movilización social, en muchos casos centradas más en la identidad y en la seguridad que en el empleo, pero que han encontrado un terreno abonado en la crisis social y el rechazo al establishment (Greven, 2016). Esas narrativas tienen varios componentes, que aparecen con distintas formas según las realidades de cada país.

En primer lugar, son narrativas antiélites - contra la clase política, los ricos o los expertos - , en las que el líder se presenta como alguien ajeno a la clase o casta política (Mudde y Rovira, 2017, p. 62), que se nutre de la crisis de legitimidad y de la falta de respuestas por parte de dichas élites a los problemas socioeconómicos de las clases medias y bajas. Como señala Pelfini (2017, p. 60), en un escenario de repolitización o de retorno de la política frente al dominio tecnocrático del neoliberalismo, cambia la retórica política y resurge lo bajo y lo plebeyo como discurso y estilo de liderazgo para simbolizar la cercanía al pueblo. Ese discurso y retórica, de la que Trump o determinados líderes de la extrema derecha europea, los brexiteers, o Bolsonaro, en el caso de Brasil, podrían ser buenos ejemplos, se alza como auténticos y sin complejos frente al discurso de las élites y los expertos, y frente a la retórica política convencional, presentada 
como discurso de corrección política, que supone un rechazo a su semántica de tolerancia e inclusión y reconocimiento y respeto de la diversidad humana. Un componente clave de estas narrativas es el rechazo a la corrupción, que permite cuestionar al conjunto de la clase política. En el caso de las elecciones en Brasil, el rechazo al PT estaba en buena medida relacionada con el proceso Lava Jato2.

También son narrativas securitarias frente al terrorismo y la inmigración, que contraponen al pueblo, la cultura y la identidad, así como la seguridad, frente al otro, construido como amenaza. Ello se nutre del giro reaccionario, tradicionalista y nativista antes descrito, que rechaza la diversidad social, y, en ocasiones, adopta expresiones abiertamente islamófobas y racistas (Bartoszewicz, 2016). En el caso de Brasil y otros países de América Latina, esta narrativa securitaria se refiere a los graves problemas de seguridad ciudadana, frente a los que se recurre, como se indicó, a visiones punitivistas con políticas de mano dura (Natanson, 2018).

La cuestión migratoria, en particular, se ha convertido en uno de los principales ejes de tensión a la hora de configurar el campo de juego de la política. En este se combinan, quizás como en ninguna otra cuestión, tanto factores socioeconómicos como socioculturales. El rechazo a la migración ha generado uno de los más efectivos discursos de movilización de los nuevos actores políticos de la extrema derecha tanto en Estados Unidos como en algunos Estados miembros de la UE. En un amplio estudio realizado en seis países de la UE, Grande et al. (2018) observan un significativo aumento de la politización de la cuestión migratoria desde los años noventa, y está relacionada más con factores de agencia, como la actuación de partidos insurgentes de la derecha radical, que con variables de estructura, como la proporción de población migrante, o el nivel de desempleo. Estos factores, siendo relevantes, no se traducirían automática o necesariamente en conflictividad política.

Por todo lo anterior, puede decirse que la crisis de los refugiados sirios de 2015 fue, en realidad, una crisis de gobernanza europea, que refleja que la pugna política al interior de la UE se ha subordinado a las narrativas securitarias sobre la inmigración impulsadas por el populismo xenófobo de extrema derecha, sea a través de los gobiernos de algunos Estados miembros, o de su creciente normalización en las posiciones y discurso de los partidos tradicionales (Sanahuja, 2016; Cecorulli y Lucarelli, 2017). En 2018, con una cifra de llegadas de apenas 55.000 personas - muy lejos de las más de un millón de tres años antes- el grado de polarización al interior de los Estados miembros, y entre ellos y las instituciones de la UE, fue aún mayor. También en 2018, la caravana de migrantes centroamericanos que a través de México se dirigía a Estados Unidos, en plena campaña electoral para las legislativas de ese país, se ha convertido en una cuestión de seguridad nacional que ha implicado incluso el despliegue de fuerzas militares. 
En ese contexto, volviendo a la UE, la política migratoria y de asilo y refugio queda reducida a un problema de seguridad y control fronterizo, con el consiguiente riesgo de desnaturalizar y envilecer el proyecto europeo, al estar ese enfoque securitario en contradicción flagrante con sus principios, metas y, compromisos y obligaciones internacionales en materia de democracia, derechos humanos, y lucha contra la pobreza y la desigualdad.

Finalmente, son narrativas antiglobalización, incluyendo la variante euroescéptica, marcadamente nacionalistas, y que reclama políticas proteccionistas frente a las normas del ordogloablismo, y rechaza las sociedades abiertas y los valores cosmopolitas. Como se señala en la siguiente sección, la movilización social y política articulada en torno a estas narrativas han contribuido a definir un nueva divisoria o clivaje político entre los partidarios de sociedades abiertas o cerradas (The Economist, 2016), en torno a valores cosmopolitas o nacionalistas, entre universalismo o particularismo, o entre políticas de integración o de demarcación (Kriesi et al., 2012b). En parte, ese clivaje también supone una reedición del más tradicional entre cosmopolitismo y comunitarismo (García Segura, 2011; Zürn y De Wilde, 2016) y se relaciona con las guerras culturales e identitarias entre liberalismo y tradición que de manera creciente polarizan el debate social y político tanto en los países avanzados como en los países emergentes al calor de los cambios sociales que comporta la globalización (Khan, 2017, p. 39).

En la propagación de estas narrativas y discursos tienen un papel clave los medios de comunicación más polarizados e ideologizados. Incide también el manejo de las emociones colectivas a través de las redes sociales (Van Wyk, 2017), cuyos algoritmos, basados en las preferencias de cada usuario, tienden a generar bucles cognitivos autorreferenciales que potencian esos discursos y crean una esfera posfactual. Esa esfera transforma la arena política en muchos países, tornándola más polarizada e ideologizada y, por ello, la aleja aún más del ideal habermasiano de esfera pública abierta al contraste de argumentos racionales en la que habría de basarse una democracia deliberativa. En una visible paradoja, el aumento de los intercambios de datos que reflejan los indicadores sobre el avance de la globalización coexiste con una internet más fragmentada, parroquial y cerrada. A ello se añaden las mayores capacidades de segmentación y direccionamiento de los mensajes electorales utilizando la minería de datos y la inteligencia artificial, como lo ilustran casos como los de las empresas Palantir o Cambridge Analytica, del grupo SCL, sobre el uso de datos personales obtenidos de la red Facebook tanto en las elecciones estadounidenses que dieron la victoria a Donald Trump, como en el referéndum del Brexit (Peirano, 2018; Guimón, 2018; Hindman, 2018; The Economist, 2018b). 
Frente a estos actores, relatos y dinámicas las élites dominantes se han mostrado a menudo insensibles e incapaces para reconocer ese descontento, afrontar los problemas sociales y reorientar las políticas que les dan origen. No han faltado voces de alarma, como el diagnóstico anual de riesgos globales del Foro Económico Mundial de Davos, que ha identificado de manera reiterada la desigualdad económica y la polarización política como uno de los más importantes riesgos sistémicos. Wolfgang Münchau (2016) señaló en Financial Times que el establishment al cuidado del orden liberal global parecía estar sumido en un momento María Antonieta, ajeno a un sistema financiero fuera de control o a los abusos fiscales de las multinacionales, abandonando a su suerte a parte de la ciudadanía, insistiendo en políticas irresponsables de austeridad o en relación con la migración, denigrando a los votantes que se inclinan hacia la extrema derecha como meros exponentes de un voto irracional, y con todo ello, se enajenan su apoyo y dan alas al ascenso de la extrema derecha.

Esa valoración no es exagerada. Ese cuestionamiento a las élites dirigentes se refleja de manera diáfana en distintas encuestas de opinión de cobertura mundial. Las encuestas antes mencionadas del programa de actitudes globales del Pew Global Research Center o de Ipsos registraban una clara divisoria entre el pesimismo reinante en los países avanzados y el optimismo de los emergentes a la hora de afrontar el futuro. Pero esas diferencias Norte-Sur desaparecen en cuanto a la valoración de las élites: datos de 2013 mostraban que el $64 \%$ de la población de Asia y de América Latina, el $77 \%$ en África subsahariana, el $60 \%$ de los estadounidenses, y el $78 \%$ de los europeos creían que el sistema económico en su país favorecía a los ricos (Pew Global Research Center, 2014). Las encuestas de Ipsos de 2016 muestran que en promedio el $76 \%$ de la población mundial consideraba que el sistema económico de su país estaba sesgado a favor de los sectores más ricos y poderosos y no respondía al interés de la sociedad en su conjunto (Duffy, 2017, p. 21-23). De los 22 países considerados, tanto emergentes como avanzados - aunque con la notable ausencia de China-, la visión menos desfavorable de las élites correspondía a Suecia, con más de la mitad de la población suscribiendo esa visión crítica, y los índices máximos correspondían al $85 \%$ de España, el $81 \%$ de Brasil, o el $94 \%$ de México, con los países del G8 muy cerca del promedio mundial. En relación con esos datos cabe mencionar que al inicio de 2018 la corrupción era el mayor motivo de preocupación a nivel mundial, mientras que el desempleo y la pobreza ocupaban el segundo y tercero, a escasa distancia, y en los dos años anteriores la corrupción se había situado en segundo lugar, por detrás del desempleo (Ipsos 2016, 2017, 2018). Finalmente, el Eurobarómetro de abril de 2018 mostraba que en el conjunto de la UE un $48 \%$ de la población consideraba que las decisiones políticas no se aplicaban de manera igualitaria, y solo un $32 \%$ consideraba lo contrario (Comisión Europea, 2018). 


\section{Globalización, nacionalismo y orden liberal: matrices y coaliciones ante el regionalismo y la política internacional}

La irrupción de estas fuerzas de extrema derecha ha tenido importantes efectos en la política y el conflicto social. Se ha afirmado que, junto a la tradicional divisoria entre izquierda y derecha, centrada en ciertos valores y en los conflictos distributivos en el ámbito social y económico, aparece un nuevo eje o clivaje fundamental marcado por las posiciones frente a la globalización, entre cosmopolitismo y nacionalismo, entre globalistas y patriotas, o entre abierto y cerrado. Esa divisoria o clivaje reinterpreta o reenmarca los conflictos redistributivos en términos de ganadores y perdedores de la globalización, y los complejiza al introducir elementos de seguridad e identidad. Todo ello fragmenta y reajusta las preferencias de los votantes, supone una amplia reorganización del campo de la política y el conflicto social, y se proyecta al ámbito exterior (The Economist, 2016, Inglehart y Norris, 2016). Ese clivaje aparecería al interior de los países, en la arena política nacional, y también entre países, en arenas de política interestatal regional, o global, como en la política europea, entre los europeístas partidarios de la globalización, abiertos y cosmopolitas; y los euroescépticos que defienden sus respectivos Estados soberanos y cuestionan los poderes supranacionales de Bruselas. Es el plano internacional, es en cuestiones como la apertura a la globalización, la integración económica, los acuerdos de libre comercio, la política migratoria, los derechos humanos, o la política exterior y de seguridad frente a viejas y nuevas amenazas como el terrorismo, donde esa divisoria aparece con más claridad, erosionando y/o poniendo en cuestión el consenso existente en el centro político en torno al internacionalismo liberal y los valores cosmopolitas en los que se ha basado la globalización como forma de orden mundial.

Ese nuevo clivaje y los alineamientos políticos a los que da origen no son en modo alguno diáfanos y no deberían llevarse demasiado lejos en el análisis: la realidad es compleja y como se ha señalado admiten múltiples variantes y modulaciones discursivas en las que juegan un papel importante las mediaciones, actores y circunstancias de cada arena política local o nacional (The Economist, $2018 a$ ). En este trabajo esa divisoria se asume por su valor heurístico, en tanto elemento que permite modelizar y ordenar el escenario político de cada país, y entre países, en relación con el cuestionamiento del orden liberal internacional y la globalización como orden hegemónico.

En un sencillo ejercicio de modelización, si se cruzan los dos ejes o clivajes - pro y antiglobalización, e izquierda y derecha - en un cuadro de doble entrada imaginario, aparecen cuatro recuadros, con las grandes matrices de política 
internacional que, con los correspondientes acentos y mediaciones nacionales y de clase social, edad, etc... pueden definir el escenario de la política y el conflicto social en un momento de crisis de globalización, sea en el plano nacional o global, y permiten ubicar los nuevos conflictos surgidos de la repolitización y contestación a elementos del orden internacional liberal y a la globalización que antes se daban por sentados. De forma simplificada, a modo de modelos de análisis, se presentan a continuación:

a. Davos o los globalistas de derechas, favorables a la democracia liberal, el libre comercio y la empresa privada: proclives a profundizar la integración económica global, y partidarios del statu quo de la globalización. Su más clara expresión es el globalismo u ordoglobalismo ideológico y normativo (Slobodian, 2018) de las élites transnacionales vinculadas a la empresa y las finanzas globales reunidas en el Foro Económico Mundial de Davos. Su expresión política se sitúa en el centro derecha y entre los sectores centristas de la socialdemocracia europea - ambas fuerzas, por ejemplo, apoyaron conjuntamente en su momento el TTIP en el Parlamento Europeo-, y los sectores más moderados del Partido Demócrata en Estados Unidos. Cuentan con el fuerte apoyo doctrinal de los organismos financieros internacionales. Su base electoral se encontraría en los sectores urbanos más cultivados y pudientes, más internacionalizados, así como en segmentos de la clase media vinculados al sector formal de la economía y los servicios, con intereses en la libre movilidad de factores, más intensivos en conocimiento y, por ello, relativamente más protegidos frente al libre comercio. Desde la crisis global los partidos que se alinean con Davos experimentan un marcado retroceso electoral, aunque en algunas regiones como América Latina, con Macri o Temer, hayan podido tener un resurgimiento relacionado con el fin del anterior ciclo de gobiernos progresistas. Frente al ascenso de los nacionalistas, estos actores, como se indicará, están tratando de articular nuevas coaliciones a favor de la globalización, pero están condicionadas por procesos electorales internos y la presión de las fuerzas de derecha en ascenso.

b. Porto Alegre o los globalistas progresistas, que incluyen a sectores de la izquierda cosmopolitas que han planteado la necesidad de regular la globalización a través de reglas regionales o globales que protejan los derechos laborales y sociales, el medio ambiente — por ejemplo, a través de una concepción de ciudadanía global respetuosa de la diversidad, o de la agenda global de desarrollo sostenible-, con una regulación inclusiva de la inmigración, basada en el reconocimiento de derechos. 
Para ello han promovido un regionalismo avanzado, con organizaciones regionales fuertes o un nuevo multilateralismo para la gobernanza justa e inclusiva de la globalización. Socialmente son también expresión de clases medias y medias altas urbanas y cultivadas, vinculadas al sector servicios, con mayor presencia de jóvenes y mujeres. Doctrinalmente se basarían en los aportes del altermundialismo y en lecturas pluralistas del cosmopolitismo neokantiano, que por ello han estado alejadas de otras lecturas que se han utilizado para sustentar el universalismo occidental (De Sousa, 2005). Incluye a los sectores progresistas de la socialdemocracia, a otras fuerzas de izquierda, a oNG globales, como Oxfam, y a movimientos como Occupy Wall Street o Welcome Refugees, a través de las coaliciones transnacionales organizadas en su momento en torno al Foro Social Mundial de Porto Alegre. En alza en los años 2000 como movimientos sociales, y en menor medida términos electorales, desde 2008 están en franco retroceso.

c. Atenas y Caracas, o los soberanistas y desglobalizadores de izquierda, que agrupan fuerzas antieuropeas y antioccidentales - Syriza, en Grecia, o en un período anterior los movimientos bolivarianos agrupados en torno a la Alianza Bolivariana de los Pueblos de Nuestra América-, así como movimientos sociales y ambientalistas que reivindican la autogestión y las economías locales. Radicalmente contrarios a la globalización, identificada con neoliberalismo, al libre comercio y a la actuación de las multinacionales, rechazan también, por su carácter hegemónico, las normas e instituciones internacionales. En la estela de la crisis registran pequeños avances en algunos países avanzados, pero retroceden en otros lugares, como América Latina.

d. Washington, Brasilia, Moscú y (con matices) Beijing constituirían ya un grupo de nuevos patriotas que representan una derecha soberanista y nacionalista, y en la UE, profundamente euroescéptica (Dennison y Pardijs, 2016); con una retórica contraria a la liberalización económica y, en ocasiones, a la gran empresa y las multinacionales; son tradicionalistas en materia de cultura, prácticas sociales y género, así como en materia religiosa; más sensibles a la política del miedo asociada al terrorismo islámico o la delincuencia común; recelosos de la diversidad social y contrarios al multiculturalismo, en mayor o menor medida nativistas, xenófobos, antiinmigración, y en ocasiones, abiertamente islamófobos. Sus líderes electos serían una expresión de nuevas formas de cesarismo 
surgidos de una crisis de hegemonía. Socialmente, agrupan a perdedores - reales o autopercibidos - de la globalización, como clases medias y medias bajas afectadas por el desempleo y la desindustrialización; y a sectores rurales y de mayor edad que rechazan el cosmopolitismo y el multiculturalismo. En el caso de China, defensores de un sistema social que ofrece empleo, orden y seguridad a cambio de libertades y conformidad social. En su visión del mundo y de la política exterior son marcadamente nacionalistas y cuestionan la sujeción a normas e instituciones multilaterales y a los acuerdos globales sobre desarrollo sostenible o cambio climático. En la defensa del interés nacional, en clave geopolítica, priman la seguridad, aunque para alcanzarla oscilan entre el aislacionismo o retrenchment y la política de poder de matriz hegemónica. Además de la extrema derecha de Europa y en Estados Unidos, el nacionalismo de Vladimir Putin en la Federación rusa, de Erdogan en Turquía, o en otros países en desarrollo, o nuevas fuerzas de derecha nacionalista, como Jair Bolsonaro en Brasil, o los grupos evangélicos en alza en América Latina son representativos de esta tendencia. Como se ha señalado, se trata de las fuerzas políticas más dinámicas, en términos de agencia, y están claramente en ascenso.

En ocasiones, algunos partidos políticos se encuentran divididos entre dos de estas matrices, y presentan distintas modulaciones de esos discursos (Dennison y Pardijs, 2016). Sería el caso de la socialdemocracia europea, escindida dentro de cada país, y entre países, entre Davos o el ordoliberalismo, por un lado; y el cosmopolitismo progresista, por otro, y puede alegarse que es una de las razones de su crisis; o de los demócratas en Estados Unidos, entre los partidarios de Hillary Clinton y de Bernie Sanders.

En la derecha nacionalista en ascenso también hay diferencias importantes entre, por ejemplo, los brexiteers, abiertamente liberales, que desean ver de nuevo al Reino Unido surcando en solitario los mares del libre comercio; el neoliberalismo descarnado que anuncia Paulo Guedes, ministro de Economía en el gobierno de Bolsonaro en Brasil; el más proteccionista Frente Nacional francés; o la más ambivalente o errática posición de Estados Unidos con Trump.

Algunos actores oscilan entre una u otra de estas matrices: es el caso de China, que apuesta por la globalización económica y al tiempo impulsa un desarrollismo tecnocrático marcadamente nacionalista que, sin embargo, es bienvenido en un Davos más neoliberal que democrático. Este país, además, tiende a formas más autoritarias, como ilustran las reformas constitucionales de marzo de 2018 y la concentración del poder en Xi Jinping, y con ello se aleja de la apertura 
democrática que según el clásico «libreto» liberal debía ser el resultado final de su desarrollo capitalista.

Estas divisorias también han sido conceptualizadas y modelizadas de otras maneras. Para Grande y Kriesi (2012, p. 3) puede ser definidas, por ejemplo, en términos de integración versus demarcación. Estos autores combinan esa divisoria con el par intervencionismo-liberalismo, lo que daría como resultado cuatro combinaciones con las correspondientes coaliciones políticas resultantes: los cosmopolitas intervencionistas (verdes, socialdemócratas, sindicatos...); los nacionalistas intervencionistas (populistas de extrema derecha, comunistas y socialistas de izquierda); los cosmopolitas neoliberales (partidos liberales, democristianos, conservadores, asociaciones empresariales...); y los nacionalistas neoliberales (populistas de derechas procedentes de antiguas fuerzas liberales y democristianas). En estos cuatro grandes grupos o coaliciones se estarían produciendo movimientos, tanto en la derecha neoliberal, como en la izquierda cosmopolita, para reposicionarse ante el mayor atractivo y capacidad de movilización de las propuestas más intervencionistas y nacionalistas (Grande y Kriesi 2012, p. 22). Esta conceptualización, sin duda sugerente y con un alto valor analítico para el examen de las posiciones y coaliciones en política interna, o en la UE, es sin embargo menos diáfana a la hora de explicar los realineamientos en política exterior y en torno a las normas e instituciones del orden internacional por lo que no se ha considerado en este análisis.

De igual manera, la arena política europea y el proceso de repolitización y polarización sociopolítica en torno a la integración europea supone enmarcados y narrativas específicas. En algunos casos, la integración europea se configura como aproximación o proxy del debate más amplio sobre la globalización —-la «Europa que protege, empodera y defiende» de Juncker o Macron, así definida como narrativa para contrarrestar otras visiones o narrativas de la UE como cárcel o tecnocracia neoliberal, antidemocrática, o uniformizadora-, pero también establece divisorias y relatos específicos que organizan las posiciones de política exterior (Hutter, Grande y Kriesi, 2016). Sería también el caso del enmarcado el debate sobre las causas de la crisis de la eurozona y las políticas a aplicar, basado en fábulas morales de cigarras y hormigas; esto es, de países virtuosos, productivos y ahorradores del Norte, y países despilfarradores y viciosos del Sur. Como afirmó el presidente del Eurogrupo, Jeroen Dijsselbloen, en una infundada, tosca y machista declaración pública, estos países no pueden pedir ayuda europea después de haber gastado el dinero en «alcohol y mujeres» (Pérez, 2017). Es quizás el renovado liderazgo europeísta de Macron el que encarna de manera más directa esas contradicciones, con un compromiso globalista cada vez más lastrado por la oposición interna a la apertura y el libre comercio, sea la más tradicional del 
sector agropecuario, la de la extrema derecha, o la que ha brotado desde finales de 2019 con la revuelta de los «chalecos amarillos».

Con todo lo anterior, la UE va a tener más difícil mantener sus valores e identidad como potencia normativa y su papel como pilar del internacionalismo liberal. Como ha señalado Mark Leonard, quedaría atrás la visión universalista de una UE cosmopolita con voluntad de transformar el mundo conforme a sus valores, dando paso a una UE basada en una nueva narrativa e identidad excepcionalista y defensiva - «una fortaleza kantiana en un mundo hobbesiano» (Leonard, 2017, p. 5) - , que reserva para sí sus logros sociales y políticos, y da prioridad a sus propios intereses y a la protección de su ciudadanía ante un mundo hostil y renuente a ser reformado.

América Latina no es ajena a estas tendencias. El ascenso de las clases medias y la reducción de la pobreza de los años anteriores supone sociedades con mayores expectativas y demandas, y una creciente insatisfacción ante las barreras que impiden o dificultan el ascenso social y el acceso a la justicia y las instituciones, y rechazo hacia las élites que se han perpetuado en el poder y han capturado el Estado en su beneficio. En la región aparecen también nuevos clivajes políticos -nacionalismo vs. cosmopolitismo o globalismo; homogeneidad vs. diversidad social, cultural y de opción sexual; en cuanto a los derechos de las mujeres; pro o antimercado-, con lo que el conflicto social y político ya no se explica solo ni principalmente a través del eje izquierda-derecha.

Por ello, también en esta región se observa una creciente desafección democrática y una amplia crisis de confianza y de representación hacia las instituciones y los partidos políticos, que recogen con claridad las encuestas de opinión. El Latinobarómetro de 2018, por ejemplo, revela que en el conjunto de la región la adhesión a la democracia como la mejor forma de gobierno ya no llegaba a la mitad de la población, con un $48 \%$ en promedio. En paralelo, la proporción de personas insatisfechas con el funcionamiento de la democracia cayó de 2009 a 2018 del $44 \%$ al $24 \%$ de la población, el nivel más bajo desde los años noventa (Corporación Latinobarómetro 2018). Estos datos ayudan a entender por qué en América Latina también se observa una creciente fragmentación política, la quiebra de los sistemas de partidos tradicionales y, en algunos casos, como Brasil, la aparición de fuerzas iliberales y de ultraderecha.

Es interesante observar cómo, tras el ciclo de gobiernos progresistas, se empieza a observar un viraje hacia la derecha, iniciado a finales de 2015 con la victoria electoral de Mauricio Macri en Argentina y, posteriormente, en agosto de 2016, con la llegada al poder de Michel Temer, tras la destitución de Dilma Rousseff en Brasil. Estos nuevos gobiernos liberal-conservadores adoptaron políticas 
exteriores favorables a la globalización y el regionalismo abierto, supuestamente desideologizadas y pragmáticas, alineadas con el orden liberal y, en su propia retórica, deseosas de volver al mundo y abrazar la globalización. Un elemento importante de su propuesta es el desmantelamiento de las organizaciones regionales del anterior regionalismo posliberal como UNASUR, y flexibilizar las existentes, como Mercosur, reduciendo a casi nada su capacidad, institucionalidad y agencia, como ha podido verse en la crisis de Venezuela, que la región parece haber delegado, en la práctica, a actores foráneos y en particular a Estados Unidos.

Estos gobiernos, sin embargo, no han encontrado las respuestas favorables que esperaba tras ese giro globalista (Sanahuja y Comini, 2018) con un sistema internacional en el que los nuevos nacionalistas están contribuyendo a cerrar la fase histórica de la globalización y amenazan el orden liberal. Con la elección de Bolsonaro, de hecho, América Latina varios gobiernos latinoamericanos (Argentina, Chile, Colombia, Ecuador y, sobre todo, Brasil) adoptan posiciones más conservadoras respecto a la migración, el género, la seguridad, o el regionalismo y la integración, como eco de las que resuenan en la UE o en Estados Unidos. La excepción a esta tendencia es, obviamente, la elección López Obrador en México. Sin embargo, es en gran medida la expresión de un voto indignado, en clave de la rebelión contra las élites que se observa a escala mundial, de la que se nutre, y a la vez retroalimenta el discurso pueblo vs. élites que también tiene su reflejo en otras latitudes.

De nuevo, estas tendencias se presentan en cada país de distinta forma, debido a particulares circunstancias y mediaciones nacionales. Pero en conjunto, más allá de las especificidades de cada momento y país, parecen sincronizar el ciclo político de América Latina, a partir de sus características, con la tendencia global de cuestionamiento de la democracia y del orden internacional liberal.

\section{Conclusiones y perspectivas}

Los procesos de contestación social y política que sustentan el ascenso de la ultraderecha y el nacionalismo parecen estar afectando más a los países avanzados que a los países emergentes, pero se trata de un ciclo global que muestra una creciente sincronización. La elección de Bolsonaro en Brasil, en particular, muestra que más allá de acentos y mediaciones nacionales existe una tendencia global de ascenso de fuerzas nacionalistas y de extrema derecha que se configura como revuelta contra el orden internacional liberal, contra el establishment que lo respalda. A modo de giro Polanyi, emergen demandas de protección al Estado y se rechazan los elementos socioculturales que caracterizan a las sociedades abiertas. Esos procesos nacionales, al proyectarse al plano internacional vía 
gobiernos, debilitan el mundo de Davos; es decir, el de las élites transnacionales que han sostenido la globalización y la integración regional, y minan el liderazgo que habían mantenido los países ricos, y en particular Estados Unidos y la UE, en el sostenimiento del orden internacional liberal.

Como se sostiene en este trabajo, la crisis de la globalización es una crisis de hegemonía y, por lo tanto, gobernanza eficaz y legítima, que se expresa al interior de cada Estado así como en el plano internacional. A través de cambios de gobierno o de su desplazamiento a la derecha se observa una clara tendencia en las políticas exteriores a la adopción de posiciones nacionalistas, menos cooperativas, y con menor capacidad de afrontar los riesgos globales. Estos cambios no significan necesariamente el cierre abrupto de ese ciclo histórico. Más de cuatro décadas de integración económica a escala global y regional no desaparecen de un día para otro, y más bien, adoptarán nuevas formas con la revolución digital. En ese escenario, el ascenso de las fuerzas de extrema derecha comporta una clara erosión del entramado de normas e instituciones, presentes y futuras, necesarias para la gobernanza del sistema internacional, y cuestiona cualquier proyecto cosmopolita orientado la necesaria reconstrucción del contrato social, y la formulación de una nueva narrativa de progreso humano para el siglo XXI.

\section{Referencias}

AtKinson, S. (2017). The Optimism Divide. En Ipsos (Ed.), Global Trends 2017. Fragmentation, Cohesion, Uncertainty (pp. 55-59). Londres, Reino Unido: Ipsos.

Bartoszewicz, M. G. (2016). Festung Europa: securitization of migration and radicalization of European Societies. Acta Universitatis Carolinae. Studia Territorialia, 2, 11-37.

Bourguignon, F., Morrison, C. (2002). Inequality among world citizens. American Economic Review, 92(4), 727-744.

Bourguignon, F. (2012). La mondialisation de l'inégalité. París, Francia: Seuil.

Cecorulli, M., Lucarelli, S. (2017). Migration and the Eu Global Strategy: Narratives and Dilemmas. The International Spectator, 52(3), 83-102.

Comisión Europea (2018). Fairness, Inequality and Integenerational Mobility. Special Eurobarometer 471. Bruselas, Bélgica: Comisión Europea.

Corporación Latinobarómetro(2018). Informe 2018. Santiago de Chile, Chile: Corporación Latinobarómetro.

Cox, R. W. (1981). Social Forces, States and World Orders: Beyond International Relations Theory. Millennium: Journal of International Studies, 10(2), 126-155. 
De Sousa Santos, B. (2005). Beyond neoliberal governance: the World Social Forum as subaltern cosmopolitan politics and legality. En B. De Sousa Santos y C. A. Rodríguez Garavito (Eds.), Low and Globalization from Below. Towards a Cosmopolitan Legality (pp. 29-63). Cambridge, Reino Unido: Cambridge University Press.

Dennison, S., PARdiJs, D. (2016). The World According to Europe's Insurgent Parties: Putin, Migration and People Power. ECFR Essays. Londres, Reino Unido: European Council on Foreign Affairs ECFR/181.

Dolezal, M. (2012). Restructuring the national political space: the supply side of European electoral politics. En H. Kriesi, E. Grande, M. Dolezal, M. Helbling, D. Hoglinger, S. Hutter, y B. Wüest (Ed.), Political Conflict in Western Europe (pp. 127-150). Cambridge, Reino Unido: Cambridge University Press.

Duffy, B. (2017). The crisis of the elites. En Ipsos (Ed.), Global Trends 2017. Fragmentation, Cohesion, Uncertainty (pp. 21-23). Londres, Reino Unido: Ipsos.

Fourastié, J. (1979). Les Trente Glorieuses, ou la révolution invisible de 1946 à 1975. París, Francia: Fayard.

Fukuyama, F. (1992). The End of History and the Last Man. Nueva York, EE. Uu.: Free Press.

GARCÉs, M. (2017). Nueva ilustración radical. Barcelona, España: Anagrama.

García Segura, C. (2011). Unidad y pluralismo en la sociedad internacional, el debate contemporáneo entre cosmopolitismo y comunitarismo. En Á. J. Rodrigo, y C. García Segura (Ed.), Unidad y pluralismo en el derecho internacional público y en la comunidad internacional (pp. 84-105). Madrid, España: Tecnos.

Guimón, P. (27 de marzo de 2018). El Brexit no habría sucedido sin Cambridge Analytica. El País. Recuperado de <https://bit.ly/2pG8IHx>.

GILL, S. (1995). Globalisation, Market Civilization and Disciplinary Neoliberalism. Millennium: Journal of International Studies, 24(3), 399-423.

Gill S. (2008). Power and Resistance in the New World Order. Londres, Reino Unido: Palgrave Macmillan.

Goldin, C., Margo, A. (1992). The Great Compression: The Wage Structure in the United States at Mid-century. Quarterly Journal on Economics, 107(1), 1-34.

GrANDE, E., KRIESI, H. (2012). The transformative power of globalization and the structure of political conflicto in Western Europe. En H. Kriesi, E. Grande, M. Dolezal, M. Helbling, D. Höglinger, S. Hutter, y B. Wüest (Ed.), Political Conflict in Western Europe (pp. 3-35). Cambridge, Reino Unido: Cambridge University Press. 
GrAnde, E., HutTER, S. (2016). Introduction: European integration and the challenge of politicisation. En S. Hutter, E. Grande, y H. Kriesi, (Ed.), Politicising Europe. Integration and Mass Politics (pp. 3-31). Cambridge, Reino Unido: Cambridge University Press.

Grande, E., Schwarzbözl, T., Fatke, M. (2018). Politizicing inmigration in Western Europe, Journal of European Public Policy, doi: <https://doi.org/10.1080/1 3501763.2018.1531909>.

Greven, T. (2016). The rise of Right-Wing Populism in Europe and the United States. A comparative Perspective. Perspective. Berlin, Alemania: Friedrich Ebert Stiftung.

Hindman, M. (10 de abril de 2018). Cómo funcionaba el modelo de Cambridge Analityca según la persona que lo construyó. El País. Recuperado de <https:// bit.ly/2JAkQlu>.

HobsBawn, E. (1995). Historia del siglo xx (1914-1991). Barcelona, España: Crítica.

HöGlinger, D., WüEst, B., y Helblig, M. (2012). Culture vs. Economy: the framing of public debates over issues related to globalization. En H. Kriesi, E. Grande, M. Dolezal, M. Helbling, D. Höglinger, S. Hutter, y B. Wüest (Ed.), Political Conflict in Western Europe (pp. 229-253). Cambridge, Reino Unido: Cambridge University Press.

Höglinger, D. (2016). Politicizing European Integration. Struggling with the Awakening Giant. Basingstoke, Reino Unido: Palgrave Macmillan.

Hutter, S., Grande, E., y Kriesi, H. (Ed.) (2016). Politicising Europe. Integration and Mass Politics. Cambridge, Reino Unido: Cambridge University Press.

IKENBERry, J. (2018). The End of the Liberal International Order. International Affairs, 24(1), 7-23.

Inglehart, R. F., Norris, P. (2016). Trump. Brexit and the rise of Populism. Economic Have-nots and Cultural Backlash. Harvard Kennedy School Faculty Research Working Papers RWP 16-026, doi: <http://dx.doi.org/10.2139/ssrn.2818659>.

IPSOs (2016). What worries the world, Londres, Reino Unido: Ipsos.

IPSOS (2017). What worries the world, Londres, Reino Unido: Ipsos.

IPSOs (2018). What worries the world, Londres, Reino Unido: Ipsos.

JAYASURIYA, K. (2010). The Strange Death of the International Liberal Order. Economic and Political Weekly, XLV(23), 75-85.

JudT, T. (2005). Postguerra. Una historia de Europa desde 1945. Madrid, España: Taurus. 
JuNCKer, J. C. (2016). Estado de la Unión 2016: hacia una Europa que proteja, empodere y vele por la seguridad. Bruselas; Bélgica: Unión Europea.

Khan, A. (2017). Me versus Us. Is the world Getting More or Less Liberal?. En Ipsos, Global Trends 2017. Fragmentation, Cohesion, Uncertainty (pp. 3941). Londres, Reino Unido: Ipsos.

KrIESI, H. (2012a). Restructuring the national political space: the suppy side of national electoral politics. En H. Kriesi, E. Grande, M. Dolezal, M. Helbling, D. Höglinger, S. Hutter, y B. Wüest (Ed.), Political Conflict in Western Europe (pp. 96-126). Cambridge, Reino Unido: Cambridge University Press.

Kriesi, H., Grande, E., Dolezal, M, Helbling, M., Höglinger, D., Hutter, S., y WüEst, B. (2012b). Political Conflict in Western Europe. Cambridge, Reino Unido: Cambridge University Press.

Krugman, P. (2007). The Conscience of a Liberal. Nueva York, EE. UU.: W. W. Norton.

Lakner, C., Milanovic, B. (2016). Global Income Distribution: From the Fall of the Berlin Wall to the Great Recession. The World Bank Economic Review, 30(2), 203-232.

LeONARD, M. (2017). L'Europe qui protège. Conceiving the next European Union. ECFR Essays. Londres, Reino Unido: European Council on Foreign Affairs ECFR/227.

Marshall, B. (2017). Uncertainty and Tradition. En Ipsos, Global Trends 2017. Fragmentation, Cohesion, Uncertainty (pp.35-37). Londres, Reino Unido: Ipsos.

Milanovic, B. (2012). Global Income Inequiality by the Numbers: In history and Now: an Overview. Policy Research Working Paper $n .^{\circ}$ 6259. Washington, EE. UU.: Banco Mundial.

Milanovic, B. (2016). Global inequality: A New approach for the Age of Globalization. Cambridge, EE. UU.: Harvard University Press.

Mudde, C., Rovira, C. (2017). Populism. A very short introduction. Oxford, Reino Unido: Oxford University Press.

Münchau, W. (27 de noviembre de 2016). The elite's Marie Antoinette moment. Right response is to focus on financial sector and inequality. Financial Times. Recuperado de $<$ https://on.ft.com/2gruico $>$.

Natanson, J. (2018). Brasil: la nueva potencia de la derecha mutante. Nueva Sociedad. Recuperado de <https://bit.ly/2VWPWd2>.

NoAH, T. (2012). The Great Divergence: America's Growing Inequality Crisis and What We Can Do about It. Nueva York, EE. UU.: Bloomsbury Press. 
OcDe (2008). Growing Unequal? Income distribution and Poverty in OECD Countries. París, Francia: OCDE.

Ocde (2011). Divided We Stand. Why Inequality Keeps Rising. París, Francia: Ocde. Ocde (2015). In It Together: Why Less Inequality Benefits All. París, Francia: Ocde.

Peirano, M. (22 de marzo de 2018). Palantir, el mayor invento de espionaje del mundo del megamillonario Peter Thiel. El Confidencial. Recuperado de $<$ https:// bit.ly/2F7BPrV>.

Pelfini, A. (2017). Trump y la ilusión de la desglobalización. En D. García Delgado y A. Gradín (Ed.), El neoliberalismo tardio. Teoría y praxis (pp. 59-64). Buenos Aires, Argentina: Clacso/Flacso.

PÉrez, C. (22 de marzo de 2017). Dijsselbloem: No puedo gastarme el dinero en alcohol y mujeres y después pedir ayuda. El País. Recuperado de $<$ https:// bit.ly/2W42AHg>.

Pew Global Research Center (2014). Emerging and developing countries much more optimistic than rich countries about the future. Washington, EE. UU.: Pew Global Research Center.

Pew Global Research Center (2018) Eastern and Western Europeans Differ on Importance of Religion, Views of Minorities, and Key Social Issues. Washington, ee. uU.: Pew Global Research Center.

Piketty, T. (2014). Capital in the Twenty-First Century. Cambridge, EE. uU.: Harvard University Press.

Polanyi, K. (2007) [1944]. La Gran Transformación. Los orígenes económicos y sociales de nuestro tiempo. Madrid, España: Fondo de Cultura Económica.

RoDRIK, D. (2011) La paradoja de la globalización. Democracia y el futuro de la economía mundial. Barcelona, España: Antoni Bosch.

Sanahuja, J. A. (2012). Las cuatro crisis de la Unión Europea. En M. Mesa (Coord.), Cambio de ciclo: crisis, resistencias y respuestas globales. Anuario CEIPAZ 2012-2013 (pp. 51-83). Madrid, España: CEIPAZ.

SAnahuja, J. A. (2013). Las nuevas geografías de la pobreza y la desigualdad y las metas de desarrollo global post-2015 En M. Mesa (Coord.), El reto de la democracia en un mundo en cambio: respuestas políticas y sociales. Anuario CeIPaz 2013-14 (pp. 61-100). Madrid, España: CeIPAZ.

Sanahuja, J. A. (2015). Los desafíos de la teoría crítica de las Relaciones Internacionales. En C. Arenal, y J. A. Sanahuja (Coord.), Teorías de las Relaciones Internacionales (pp. 157-188). Madrid, España: Tecnos. 
SAnahuJA, J. A. (2016). La Unión Europea y la crisis de los refugiados: fallas de gobernanza, securitización, y diplomacia de chequera. En M. Mesa (Coord.), Retos inaplazables en el sistema internacional. Anuario CEIPAZ 2015-2016 (pp. 71-105). Madrid, España: CEIPAZ.

Sanahuja, J. A. (2017). Posglobalización y ascenso de la extrema derecha: crisis de hegemonía y riesgos sistémicos. En M. Mesa (Coord.), Seguridad internacional y democracia: guerras, militarización y fronteras. Anuario CEIPAZ 2016-17 (pp. 35-71). Madrid, España: CeIPAZ.

Sanahuja, J. A. (2018). La Unión Europea y la crisis de los refugiados: fallas de gobernanza, securitización y 'diplomacia de chequera'. En M. Mesa (coord.), Retos inaplazables en el sistema internacional. Anuario CEIPAZ 2015-16 (pp. 71-105). Madrid, España: CEIPAZ.

Sanahuja, J. A. (2019) [En prensa]. América Latina: malestar democrático y retos de la crisis de la globalización. En AAVv, Panorama Estratégico 2019. Madrid, España: Instituto Español de Estudios Estratégicos (IEEE).

Slobodian, Q. (2018) Globalists: The End of Empire and the Birth of Neoliberalism. Harvard, EE. UU.: Harvard University Press

TALEB, N. N. (2010). The Black Swan. The Impact of the Highly Improbable. Nueva York, EE. UU.: Penguin.

The ECONOMIST (30 de julio de 2016). Drawbridges up. The new divide in rich countries is not between left and right but between open and closed. The economist. Recuperado de $<$ https://econ.st/2Dvhqz2>.

The ECONOMIST (16 de mayo 2018a). Some thoughts on the open v close divide: it is not as simple as it seems. The economist. Recuperado de $<$ https://econ. $\mathrm{st} / 2 \mathrm{~W} 0 \mathrm{aktK}>$.

The ECONOMIST (22 de marzo de 2018b). The Facebook scandal could change politics as well as the Internet. The economist. Recuperado de $<$ https://econ. $\mathrm{st} / 2 \mathrm{UBht} 1 \mathrm{~W}>$.

VAN WyK, J. (2 de junio de 2017). The politics of anger in a angry world. Mail \& Guardian, p. 19.

ZüRN, M. (2014). The politicization of world politics and its effects: Eight propositions. European Political Science Review, 6(1), 47-71.

ZüRN, M., WILDE, P. (2016). Debating Globalization: Cosmopolitanism and Communitarianism as Political Ideologies. Journal of Political Ideologies, 21(3), 280-301.

El autor es el único responsable del artículo. 